\title{
Flexibilização das relações de trabalho via acordo coletivo ou desregulamentação dos direitos trabalhistas?
}

\section{Flexibility in labor relations via collective agreement or deregulation of labor rights?}

\author{
Walter Perpétuo Ribas \\ Universidade Estadual de Ponta Grossa - UEPG - Ponta Grossa - Brasil \\ walterperpetuoribas@hotmail.com \\ Monique Krubniki \\ Universidade Estadual de Ponta Grossa - UEPG - Ponta Grossa - Brasil \\ monique krubniki@hotmail.com \\ Josilene Aparecida Soares de Freitas \\ Escola Estadual General Antonio Sampaio - Ponta Grossa - Brasil \\ josuska73@gmail.com \\ João Irineu de Resende Miranda \\ Universidade Estadual de Ponta Grossa - UEPG - Ponta Grossa - Brasil \\ joaoirineu78@gmail.com
}

\begin{abstract}
Resumo
Este artigo tem como objetivo apresentar a polêmica em torno da flexibilização das normas trabalhistas como um dos fatores que denotam a substituição de regras imperativas pela liberdade de negociar nas relações de trabalho. Em tempos de globalização, automação, tecnologia, informalidade, e outros fatores, a flexibilização ganhou destaque no Direito do Trabalho, por ser maleável e que se adapta às circunstâncias. O governo federal apregoando a necessidade de alterar a legislação trabalhista manifestou-se através do lançamento do Projeto-lei n. 5483/2001, para alterar o artigo 618 da CLT e estabelecer a prevalência de convenção ou acordo coletivo de trabalho sobre a legislação. Visa à negociação de direitos celetistas sob o pretexto de mantença de empregos e criação de novas regras no mercado de trabalho que realizadas por acordos coletivos, ainda que não sigam as regras do ordenamento jurídico, não poderão ser declaradas ilegais. Tornou-se um tema controvertido, gerando correntes doutrinárias antagônicas. Há aqueles que a defendem, tendo como respaldo o desemprego e há aqueles que a repudiam, justificando que a flexibilização possui o poder de mitigar direitos dos trabalhadores. Verifica-se que a flexibilização dos direitos laborais enfraquece a intervenção estatal na ordem econômica e social, fazendo rever o modelo típico da relação de trabalho, com ênfase na autonomia da vontade. O direito laboral não se subtrai da realidade econômica, política e social, dado que a regulação dos direitos e deveres dos sujeitos da relação empregatícia evolui sob pressão destes. Por isto, não se pode admitir que haja retrocesso na legislação.
\end{abstract}

Palavras-chave: flexibilização, acordos coletivos, direitos laborais. 


\begin{abstract}
This article aims to present the controversy surrounding the relaxation of labor standards as one of the factors that denote the substitution of imperative rules for the freedom to negotiate in labor relations. In times of globalization, automation, technology, informality, and other factors, flexibilization has gained prominence in Labor Law, as it is malleable and adapts to circumstances. The federal government, proclaiming the need to change labor legislation, manifested itself through the launch of Bill no. 5483/2001, to amend article 618 of the CLT and establish the prevalence of collective bargaining agreement or agreement over legislation by collective agreements, even if they do not follow the rules of the legal system, they cannot be declared illegal. It became a controversial topic, generating antagonistic doctrinal currents. There are those who defend it, supported by unemployment and there are those who repudiate it, justifying that flexibilization has the power to mitigate workers' rights. It appears that the flexibilization of labor rights weakens state intervention in the economic and social order, revising the typical model of the employment relationship, with an emphasis on the autonomy of the will. Labor law is not removed from the economic, political and social reality, given that the regulation of the rights and duties of the subjects of the employment relationship evolves under pressure from them. For this reason, it cannot be admitted that there is a setback in the legislation.
\end{abstract}

Keywords: flexibility, collective agreements, labor rights.

\title{
1. Introdução
}

Etimologicamente, a palavra flexibilização é um neologismo. Nos dicionários não existe este termo, apenas a palavra flexibilidade, do latim flexibilitate, significando a qualidade de ser flexível, que tem elasticidade, destreza, agilidade, flexão, flexura, facilidade de ser manejado, maleabilidade. A outra palavra que consta nos dicionários é flexibilizar, definida como o ato de tornar flexível. ${ }^{1}$ Assim, a flexibilização ganha definições conforme as diferentes situações em que é analisada, do ponto de vista sociológico, ela é a capacidade de renúncia a determinados costumes e de adaptação a novas situações. No Direito do Trabalho, a doutrina possui vários conceitos sobre a flexibilização, mas prevalece a definição de que é uma reação aos padrões vigentes das legislações extremamente rígidas que não conseguem resolver todos os problemas trabalhistas, principalmente diante das crises econômicas.

Com este conceito a flexibilização firma-se na seara jurídica trabalhista como conjunto de regras que tem por objetivo instituir mecanismos tendentes a compatibilizar as mudanças de ordem econômica, tecnológica, política ou social existentes na relação entre o capital e o trabalho. Em uma acepção mais condescendente a flexibilização é considerada como um conjunto de regras ao trabalhador, procurando-se resguardar a sobrevivência da empresa, por meio da modificação de comandos legais, outorgando aos trabalhadores certos direitos mínimos e ao empregador a possibilidade de adaptação de seu negócio, mormente em épocas de crise econômica.

A Constituição Federal de 1988 menciona o termo flexibilização dos direitos trabalhistas em seu artigo $7^{\circ}$, prevendo-a nas hipóteses em que, de forma expressa, ressalvam o disposto em convenção ou acordo coletivo, isto é, os incisos VI, XIII, e XIV, que tratam da irredutibilidade do salário, da jornada de trabalho, e dos turnos ininterruptos de revezamento.

\footnotetext{
${ }_{1}^{1}$ FERREIRA, A. B. de H. Dicionário Aurélio Eletrônico, Versão 2.0, Nova Fronteira, 1996, CD ROM.
} 
Assim, é pelo acordo coletivo que o legislador constitucional acolheu a flexibilização dos direitos trabalhistas, considerando-a como uma forma de abrir canais para administrar a crise da relação trabalho $x$ capital que decorre de fatores econômicos, tecnológicos e sociais. Sob a perspectiva do quadro economicamente hostil que o Brasil adentrou nas últimas décadas, a legislação laboral transformou-se em entraves, às vezes insuportáveis às empresas, levando às demissões e impedindo novas contratações, o que gerou desemprego, trabalho informal, subempregos, sonegação, criminalidade, instabilidade social. Tal situação incentivou para o governo levar à pauta projeto-lei que modificaria o texto do artigo 618 da Consolidação das Leis do Trabalho (CLT), de forma a que não se tornasse ilegal criar novas formas de contratação e de organização do serviço.

A votação para aprovação deste projeto tem gerado muita polêmica doutrinária, muitas vozes se contradizem quanto à sua legalidade. Enquanto alguns veem como uma usurpação de direitos arduamente conquistados pelos trabalhadores, outros veem como uma adaptação das relações de trabalho a uma nova situação, determinada por uma economia inserida num contexto internacional voltado para a competitividade, a redução de custos em escala global e a introdução de novos sistemas operacionais com a alta evolução da tecnologia.

$\mathrm{Na}$ breve discussão aqui estabelecida, busca-se apresentar estas duas correntes doutrinárias, mencionando eminentes doutos do Direito do Trabalho sobre as razões que os levam a defender pontos de vista tão contraditórios.

\section{Desenvolvimento}

\subsection{Regulação das relações de trabalho}

A regulação das relações de trabalho tem uma trajetória histórica que vem desde a Revolução Industrial (Século XVIII), e segundo Arion Sayon Romita ${ }^{2}$ foi sendo amplamente absorvida pela crença de que estas relações representavam uma manifestação da luta de classes e um constante temor de que as repercussões dessa luta afetassem o conjunto da sociedade. Os incessantes movimentos em prol de melhores condições de trabalho manifestados a partir do Século XVIII levou a que a intervenção do Estado no relacionamento entre patrões e empregados fosse concebida como um meio de elaborar uma regulação detalhada das condições de trabalho, a fim de tornar desnecessária a atuação sindical e, por outro lado, de condicionar as partes a buscar no Estado a solução dos seus conflitos.

O Estado passou a exercer as funções básicas de conceder os direitos, fiscalizar, regular e arbitrar os conflitos. A partir de então, a política e a postura de cada governante tornou esta intervenção cada vez mais relevante, a ponto de a heterorregulação ser a característica básica da regulação das relações de trabalho, o que, em consequência provocou a rigidez da legislação, e mesmo sendo reconhecida a existência de fenômenos de interação coletiva, eles foram relegados a plano distante. No Brasil esta situação foi bem sentida com o evento da Consolidação das Leis do Trabalho (CLT).

A CLT, segundo Evaristo de Moraes Filho ${ }^{3}$ é considerada como uma legislação social que honrou a cultura do povo brasileiro em nível internacional, pela sua eficiência, pela modernidade de seus princípios, pela sua adequação às peculiaridades nacionais e, principalmente, pelo alto espírito de justiça social, que a inspirou. Ela reuniu e ordenou sistematicamente todas as leis reguladoras do trabalho, assistência social e respectivos aparelhos, nacionalizando o trabalho e regulando inclusive a sindicalização de classes

\footnotetext{
${ }^{2}$ ROMITA, A. S. Direitos fundamentais nas relações de trabalho. São Paulo: LTr. 2001.

${ }^{3}$ MORAES FILHO, E. Introdução ao Direito do Trabalho. 5. ed., São Paulo: LTr, 2000.
} 
profissionais. Fez com que o Brasil fosse detentor de uma legislação trabalhista das mais adiantadas, tornando-o um país pioneiro em inovações sociais.

Promulgada na década de 1940, a CLT conviveu com 3 constituições, sendo que todas elas preservaram seus dispositivos e ainda incentivou a edição de novas leis de proteção trabalhista no âmbito da legislação ordinária. Em 5 de outubro de 1988 foi aprovada a atual Constituição que além de conservar o que as constituições anteriores assimilaram da CLT, criou muitos outros artigos, para garantir a segurança social e econômica dos trabalhadores. Inclusive, dedicou aos direitos trabalhistas o Capítulo II, "Dos Direitos Sociais", do Título II, "Dos Direitos e Garantias Fundamentais", ampliando o que ocorrera nas constituições anteriores em que os direitos trabalhistas sempre eram inseridos apenas no âmbito da ordem econômica. Diante destes institutos consagrou-se a proteção ao trabalhador vinculando todos os empregadores a deveres sociais suficientes para que a prestação de seus serviços fosse amparada contra quaisquer abusos, seja de ordem econômica, seja de ordem social.

Foi com este quadro protetivo aos trabalhadores que a sociedade brasileira, adentrou no processo de globalização, avanço tecnológico e outras grandes transformações que ocorreram nas últimas décadas do século passado e e a entrada do atual.

A aproximação entre os países através da globalização e o aumento da competitividade levou as empresas em busca de reduzir custos através do enxugamento do quadro funcional, dar preferência pela terceirização concentrando-se na atividade-fim, na eliminação de mão-de-obra onerosa, na automatização dos serviços e outras medidas que significaram uma total transformação nas relações de trabalho. Também se pode citar que as inovações técnicas e tecnológicas no processo de industrialização, apesar de permitirem o afastamento do homem de atividades parceladas, repetitivas, monótonas, insalubres, perigosas e prejudiciais à saúde física e/ou mental, vem levando à diminuição de empregos. Destarte, a melhoria da qualidade de vida dos trabalhadores, seja no meioambiente de trabalho, seja no convívio familiar e social foi uma das molas propulsoras da implantação de novas tecnologias.

Uma das consequências mais dramáticas desta transformação foi o desemprego, que obrigou a política social abrir canais para administrar a crise sem deixar de estimular a implantação das novas tecnologias.

Este processo foi a abertura para que o sistema protetivo, montado já há mais de meio século no Brasil, e reforçado pela Constituição Federal de 1988, venha sendo objeto de paulatina desconstrução, através de sucessivas alterações propostas pelo governo federal, sempre no sentido desregulatório e flexibilizante. Pode-se citar exemplos do que já vem acontecendo: demissão temporária, regime de trabalho em tempo parcial, fim da política salarial, restrição do poder normativo da Justiça do Trabalho. Muitas dessas alterações têm sido feitas por ação direta do executivo, através de medidas provisórias.

Tenta-se, modernamente, reagir contra este estado de coisas, sugerindo a flexibilização considerando-a como adaptabilidade, capacidade de ajustar as normas de Direito do Trabalho à realidade atual, esse interferindo como instrumento para a regulação democrática das relações de trabalho, por intermédio da participação dos agentes sociais.

\subsection{Flexibilização - instrumento de mudanças nas relaçoes de trabalho}

As hipóteses de flexibilização foram previstas pela Constituição Federal de 1988 em seu artigo $7^{\circ}$ em diferentes incisos, tais como: direitos do empregado em relação à irredutibilidade do salário (artigo $7^{\circ}, \mathrm{VI}$ ), à duração da jornada de 8 horas e à carga horária semanal de 44 horas, quando previstas em acordo ou convenção coletiva (artigo 7ํㅜ, XIII); à jornada de turnos ininterruptos, que é de 6 horas e pode ser objeto de negociação 
coletiva (artigo 7ํㅡ. XIV). São previstas, ainda, a flexibilização do dia de repouso semanal, e principalmente são reconhecidos acordos e convenções coletivas (artigo $7^{\circ}$, XXVI)

No entanto, com a transformação das relações de trabalho que vem acontecendo como foi mencionado no tópico anterior, a flexibilização via acordo coletivo tem ampliado sobremaneira os dispositivos previstos pelo legislador constitucional. $O$ que se tem observado são alterações na legislação trabalhista, tendo como fundamento o discurso do combate ao desemprego e de que se faz necessária a flexibilização dos direitos trabalhistas devido à que a mperatividade das normas laborais impede a completa adequação das empresas ao esquema do mercado atual, na medida em que não comportam alterações pela vontade dos interessados para o enfrentamento dos momentos de queda da demanda. Considerada como uma adaptação do direito do trabalho às novas realidades sociais, tem-se a tese flexibilizadora como um princípio cuja finalidade é a manutenção do equilíbrio essencial entre o jurídico e o social e perfeitamente possível harmonizar-se com outros princípios consagrados historicamente pelo direito do trabalho, permitindo que a modernização da produção não atinja as diretrizes essenciais deste ramo da ciência jurídica.

$\mathrm{Na}$ concepção de Rosita de Nazaré Sidrim Nsssar ${ }^{4}$, a flexibilização das normas trabalhistas insurge como parte integrante do processo maior de flexibilização do mercado de trabalho, buscando dotar o direito laboral de novos mecanismos capazes de compatibilizá-lo com as mudanças decorrentes de fatores de ordem econômica, tecnológica ou de natureza diversa exigentes de pronto ajustamento. Para a eminente doutrinadora, a flexibilização das normas trabalhistas não se exaure ou traduz a totalidade do fenômeno da flexibilização; já que este é bem mais abrangente compreendendo estratégias políticas, econômicas e sociais e não apenas jurídicas, atuando através de procedimentos variados e reunindo medidas com o objetivo de propiciar o rápido amoldoamento do complexo normativo laboral às mudanças decorrentes das flutuações econômicas, evoluções tecnológicas ou quaisquer outras alterações que requeiram imediata adequação da norma jurídica.

A flexibilização, segundo Márcia da Silva Costa $^{5}$ seria então, o instrumento ideológico neoliberal e pragmático que vem servindo países de economia de mercado, para que as empresas possam contar com mecanismos capazes de compatibilizar seus interesses e os dos seus trabalhadores, tendo em vista a conjuntura mundial, caracterizada pelas rápidas flutuações do sistema econômico, pelo aparecimento de novas tecnologias e outros fatores que exigem ajustes inadiáveis.

Teoricamente a flexibilização contempla inúmeras formas de modificação no direito do trabalho, que traz para a discussão doutrinária, não somente as benesses, mas também os malefícios. Alguns doutrinadores são veementes em apontar esses malefícios, pelo uso indiscriminado da flexibilização que vem ocorrendo nos últimos tempos, como é o caso de Mauro Cesar Martins de Souza 6 quando denuncia os reflexos da flexibilização do direito do trabalho, como sendo: multiplicação de contratos atípicos; maior incidência dos contratos de tempo parcial; debilitação do princípio da estabilidade; maior utilização dos contratos por prazo determinado; difusão da subcontratação; elastecimento da economia submersa; ambivalência da convenção coletiva; revisão da seguridade social, com vistas à contenção das despesas respectivas.

\footnotetext{
4 NASSAR, R. de N. S. Flexibilização do direito do trabalho. São Paulo: LTr. 1992.

5 COSTA, M. S.Reestruturação produtiva, sindicatos e a flexibilização das relações de trabalho no Brasil. RAE-eletrônica, v. 2, n. 2, art. 10, p. 1-16, $2003 . \quad$ Disponível em; http://www.spell.org.br/documentos/ver/30245/reestruturacao-produtiva--sindicatos-e-a-flexibilizacao-dasrelacoes-de-trabalho-no-brasil/i/pt-br. Acesso em: 27 de outubro de 2020.

6 SOUZA, M. C. M. de. Flexibilização da jornada em turnos ininterruptos de revezamento mediante negociação coletiva. Revista Justiça do Trabalho. Brasília, v. 214, n.1, p. 2-21, out. 2001.
} 
Verificando-se o rol apresentado pelo autor afigura-se verdadeiro que se a flexibilização do direito do trabalho possui vantagens, o número de desvantagens é enormemente maior porque, se de um lado ela pode possibilitar o incremento da ocupação da mão-de-obra em quantidade, de outro reduz drasticamente no aspecto qualitativo.

É justamente este aspecto qualitativo que é discutido nas polêmicas que giram em torno da pretensão do governo em alterar o artigo 618 da CLT, conforme será apresentado a seguir.

\subsection{Posiocionamento em relação a alteração das normas mediante acordo coletivo}

Resumidamente pode-se entender a flexibilização como um fenômeno que possibilita a alteração dos direitos dos trabalhadores através de negociação coletiva, até então prevista na Constituição Federal de 1988 e na CLT com certos limites, considerando as peculiaridades de cada categoria profissional, sem prejudicar os direitos já conquistados por cada classe trabalhadora. Com a discussão no Congresso Nacional do projeto-lei n. $5438 / 01^{7}$, que busca modificar o artigo 618 da CLT para que seja permitido as condições de trabalho serem ajustadas entre os trabalhadores e os empregadores, através de instrumentos coletivos (convenção ou acordo), e que estes prevaleçam sobre o disposto em lei.

A justificativa desta alteração é a de que haverá aumento de empregos e redução da informalidade, no entanto esta justificativa não está sendo absoltamente acatada pelos doutrinadores. Surge então uma discussão com duas correntes claramente opostas, que levam à reflexão as consequências de uma negociação por acordo coletivo, desprovida da rigidez das normas trabalhistas.

Entre os doutrinadores favoráveis à modificação do artigo 618 da CLT, pode-se citar o eminente juiz trabalhista Luiz Carlos Amorim Robortella ${ }^{8}$ que entende a flexibilização dos direitos trabalhistas como fator de sobrevivência econômica; e que representa os interesses do trabalhador já que eles podem ser defendidos pelos entes coletivos, no exercício da autonomia privada. Os motivos apresentados por este juiz para defender o uso da flexibilização seriam: o aumento do desemprego; a tendência à formação de forte economia submersa, informal; fuga da rigidez da lei; velocidade das mudanças tecnológicas; competição econômica no plano internacional e os imperativos do desenvolvimento econômico.

Sergio Pinto Martins ${ }^{9}$ apregoa que a flexibilização dos direitos trabalhistas tem por base a ideia de que a rigidez das normas laborais impede a completa adequação das empresas ao esquema do mercado mundial, na medida em que tais normas não

\footnotetext{
7 Depois dos tramites do Projeto Lei n. 5438/01, consta no Senado a seguinte redação: Altera o art. 618 da Consolidação das Leis do Trabalho - CLT (Dispõe sobre convenção ou acordo coletivo de trabalho). Art. 1․ $\mathrm{O}$ art. 618 da Consolidação das Leis do Trabalho, aprovada pelo Decreto-lei n. 5.452, de 1을 de maio de 1943, passa a vigorar com a seguinte redação: "Art. 618. Na ausência de convenção ou acordo coletivo firmados por manifestação expressa da vontade das partes e observadas as demais disposições do Título VI desta Consolidação, a lei regulará as condições de trabalho. § 1ํ A convenção ou acordo coletivo, respeitados os direitos trabalhistas previstos na Constituição Federal, não podem contrariar lei complementar, as Leis n. 6.321, de 14 de abril de 1976, e n. 7.418, de 16 de dezembro de 1995, a legislação tributária, a previdenciária e a relativa ao Fundo de Garantia do Tempo de Serviço - FGTS, bem como as normas de segurança e saúde do trabalho. $\S 2^{\circ}$ Os sindicatos poderão solicitar o apoio e o acompanhamento da central sindical, da confederação ou federação a que estiverem filiados quando da negociação de convenção ou acordo coletivo previstos no presente artigo". (NR) Art. $2{ }^{\circ}$. Esta lei entra em vigor na data de sua publicação e tem vigência de dois anos. Diário do Senado Federal, Brasília, 12 dez. 2001. p. 30652. (INTELLIGENTIA JURÍDICA). Disponível em: <www.intelligentiajuridica.com.br/v3/artigo_ visualizar.php>. Acesso em 5 mar. 2020.

${ }^{8}$ ROBORTELLA, L C. A. O moderno direito do trabalho. São Paulo, LTr, 2002.

${ }_{9}$ MARTINS, S. P. Flexibilização das condições de trabalho. São Paulo: Atlas, 2005.
} 
comportam alterações pela vontade dos interessados para o enfrentamento dos momentos de queda da demanda. Considerando a concepção da flexibilização como um princípio implícito no ordenamento jurídico, o doutrinador citado enfatiza seu sopesamento ou sua harmonização com outros princípios consagrados historicamente pelo direito do trabalho, como forma de a modernização da produção não atingir negativamente as diretrizes essenciais do direito do trabalho.

Este jurista ainda argumenta que a flexibilização das normas do direito do trabalho visa assegurar um conjunto de regras mínimas ao trabalhador e, em contrapartida, a sobrevivência da empresa, por meio da modificação de comandos legais, procurando outorgar aos trabalhadores certos direitos mínimos e ao empregador a possibilidade de adaptação de seu negócio, mormente em épocas de crise econômica. Para ele, a legalização da flexibilização está no fato de que os sistemas legais preveem fórmulas opcionais ou flexíveis de estipulação de condições de trabalho, seja pelos instrumentos de negociação coletiva, ou pelos contratos individuais de trabalho, seja pelos próprios empresários.

De uma maneira geral, os doutrinadores favoráveis à flexibilização das normas trabalhistas argumentam que os avanços das conquistas trabalhistas tornaram-se excessivamente onerosos para as empresas e isto contribui para que haja desemprego, urge, portanto, substituir o sistema atual, permitindo a prevalência do processo negocial sobre o processo estatal de formação das normas jurídicas, ou seja, o negociado prevalecendo sobre o legislado. Pelo acordo coletivo evita-se a interferência do Estado, dando-se credibilidade às forças das organizações sindicais para dialogar e substituir a rígida técnica de regulação através da lei por acordos e convenções coletivas. Sustentam ainda que, a possibilidade de utilizar esta flexibilização, nos casos com empresas com dificuldades econômicas, é de grande valor para os empregados, pois será mais favorável continuar empregado em condições inferiores do que transformar-se em desempregado. O consenso entre estes defensores da flexibilização é o aumento de emprego que tais medidas podem gerar.

Em posicionamento contrário, conforme afirma Dorothée Susanne Rudiger ${ }^{10}$, situase a Organização Internacional do Trabalho - OIT por entender que na flexibilização das relações do trabalho acontece a renúncia de direitos já adquiridos e consagrados pelos trabalhadores, tornando-se um fenômeno predatório e, em última instância antiprodutivo, uma vez que não investe no aprimoramento da mão-de-obra e a deixa marginalizada e insegura. A OIT contra-argumenta colocando que a competitividade através de relações de trabalho precárias tem um efeito perverso: beneficia o crescimento apenas a curto prazo, a longo prazo, destrói a capacidade da mão-de-obra, o que é nocivo para a economia como um todo. Para a OIT a reorganização do mercado de trabalho via negociação coletiva tem papel fundamental somente se contribuir para o aprimoramento da mão-de-obra e para o aumento da competitividade das empresas através da participação de seu pessoal nas decisões por elas tomadas.

De acordo com o ex-presidente do TST, Almir Pazzianotto ${ }^{11}$ se aprovada a decisão de alterar o artigo 618 da CLT, haverá regressão a uma fase anterior à CLT, retomandose ao velho Código Civil de 1916, que tratava as partes com absoluta igualdade de condições - desde que maior, desde que capaz, poderia contratar em igualdade de condições. No entendimento deste eminente doutor, abandonar as garantias fundamentais é extremamente perigoso e até ruinoso para a classe trabalhadora e para a economia brasileira, porque não pode ser esquecido que a massa trabalhadora compõe a

10 RÜDIGER, Dorothée Susanne. Contrato coletivo e flexibilização do mercado de trabalho. Síntese Trabalhista, São Paulo, v.8, n.110, p. 147-153, nov. 2001.

$11 \mathrm{KREIN}$, J. D. O aprofundamento da flexibilização das relações de trabalho no Brasil nos anos 90. 2001. 230 f. Dissertação (Mestrado em Economia). Instituto de Economia. Universidade Estadual de Campinas. Instituto de Economia. Campinas. 
grande massa consumidora e, portanto, precisa de poder aquisitivo. A flexibilização das relações de trabalho entregue indiscriminadamente a acordo coletivo, pode trazer redução dos direitos trabalhistas, provocando um prejuízo econômico para toda a sociedade, eis que menos direitos trabalhistas representam acumulação de riqueza e, consequentemente, mais problemas sociais, impedindo o desenvolvimento econômico, até porque os trabalhadores são, em última análise, os consumidores dos quais o capital precisa para sobreviver. Está aí a realidade a demonstrar que as técnicas de flexibilização do direito do trabalho, ao contrário de atacarem o problema do desemprego, têm alimentado a própria lógica do desemprego e provocado uma crescente desvalorização do trabalho humano, o que, por certo, está gerando o agravamento do maior problema social: a má distribuição de renda - há uma camada cada vez maior de miseráveis e uma camada cada vez menor de pessoas cada vez mais ricas. O alerta de Almir Pazzianotto é de que as normas coletivas estão, a cada ano que passa, reduzindo mais os direitos dos trabalhadores e a própria legislação tem sido interpretada de forma cada vez menos favorável ao trabalhador, alimentando-se a lógica do desemprego e aumentando a pobreza dos trabalhadores como uma bola de neve.

Everaldo Gaspar Lopes de Andrade ${ }^{12}$ contesta as ideias favoráveis à flexibilização, alegando que não se pode falar em livre negociação num ambiente marcado pelo desemprego ou subemprego, pela miséria, pelos salários baixos, pela concentração de rendas, pelos índices alarmantes de lucratividade dos empresários, pois um acordo coletivo com uma das partes enfraquecida, preocupada em preservar os empregos existentes e ameaçada pela instabilidade e pela imensa legião de desempregos que batem as portas das fábricas, não há qualquer possibilidade de sucesso, no sentido de implementar melhorias nas condições de vida e de trabalho. A livre negociação no discurso da flexibilização é utópica, pois o trabalhador como hipossuficiente estará sempre na ponta mais fraca das relações de trabalho.

Corrobora com este posicionamento, José Carlos Lima da Motta ${ }^{13}$ quando afirma que a flexibilização é um fenômeno que só floresce em países ricos, onde a participação dos trabalhadores é intensa, as convenções são bastante desenvolvidas e os sistemas de seguridade social são muito eficientes. Para este doutrinador, no Brasil, a assimilação da flexibilização no sentido de eliminação ou atenuação da proteção legal ao trabalhador, com o objetivo de aumentar emprego, somente fomenta $o$ investimento e a competitividade das empresas.

Resumidamente a corrente doutrinária contra modificação do artigo 618 da CLT apoia-se no argumento que mesmo que a legislação do trabalho tenha que estar mais aberta à economia e às necessidades de adaptação conjuntural, não é admissível que haja recuo nas conquistas dos trabalhadores, nem que sejam retiradas conquistas que se pensava estarem solidamente implantadas. A Constituição Federal de 1988 previu a flexibilização das normas trabalhistas em parâmetros tais que não fosse permitido 0 retrocesso, apenas para garantir adaptação de um Estado menos centralizado, mais aberto aos grupos naturais e mais preocupado com a eficácia e bem estar da comunidade como um todo e não apenas de uma parcela de privilegiados.

O entendimento generalizado da corrente contrária à reforma do artigo 618 da CLT é de que a flexibilização via acordo coletivo poderá ser realizada a qualquer pretexto do empresário, sem que a precarização da qualidade do trabalho aos trabalhadores seja levada em conta. O que se observa, mesmo sem o projeto ter transformando-se em lei, que todo o processo de profundo avanço jurídico observado na Constituição Federal de

\footnotetext{
${ }^{12}$ ANDRADE, E. G. L. de. Direito do trabalho e pós modernidade. São Paulo: LTr, 2005.

${ }^{13}$ MOTTA, J. C. L. da. Negociado ou legislado - uma análise crítica: o Projeto de Lei n 5.483/2001 e suas repercussões na ordem social vigente. Jus Navigandi, Teresina, v. 6, n. 58, p 1-26, ago. 2002. Disponível em: <http://jus2.uol.com.br/doutrina/texto.asp?id=3141>. Acesso em: 10 mar. 2008.
} 
1988 está sendo corroído por normas autônomas, oriundas de ajuste coletivo, que estão a invalidar os mecanismos protetivos dados pelo texto constitucional aos trabalhadores.

\section{Considerações finais}

Da pesquisa para o estudo aqui exposto conclui-se que a Constituição Federal de 1988 buscou privilegiar a negociação coletiva, valorizando os acertos diretos confeccionados pelas categorias, independente de intervenção estatal, destituindo em momentos oportunos a rigidez imposta pelas leis emanadas do Estado, permitindo maior flexibilidade para dar solução dos conflitos entre o capital e o trabalho. Pela negociação coletiva, o legislador constituinte sugeriu o reencontro dos sindicatos com as suas bases, fortalecendo o movimento sindical e resgatando a sua representatividade, garantindo, assim, uma verdadeira e legítima negociação, com igualdade entre as partes envolvidas e, consequentemente, com o cumprimento do que foi negociado. Pelos normativos constituintes a ordem jurídica reconhece a autonomia coletiva dos particulares ou autonomia privada coletiva como fonte de produção do direito, fundamentada na liberdade sindical, propondo-se um processo que conduz à celebração de um ajuste coletivo, um contrato normativo, que pode se dar através da convenção coletiva de trabalho ou do acordo coletivo de trabalho, gerando efeitos obrigacional, normativo e constitutivo, aptos a legitimar ajustes fora dos esquemas rígidos impostos pela legislação imperativa.

Todavia todas estas benesses do acordo coletivo, a flexibilização das normas trabalhista via esta negociação coletiva não está sendo absolutamente assimilada pela doutrina pátria. Muitas são as vozes contrárias Projeto-lei n. 5483/2001, que almeja ampliar os processos de flexibilização das normas trabalhistas, fazendo sobressair 0 negociado pelo legislado.

Antes da Constituição Federal de 1988, o sistema normativo brasileiro adotava o modelo legislado, o que fez com que pouco se exercitasse a negociação coletiva e, mesmo quando acordos e convenções coletivas de trabalho eram celebrados, todos os trâmites da celebração estavam disciplinados pela lei. Com o advento da Constituição Federal de 1988, pretendeu-se adotar o modelo jurídico misto, pelo qual se admite a fonte negocial em detrimento da fonte legal, rompendo com a tradição do intervencionismo estatal. Contudo, os processos que vêm sendo utilizados pela flexibilização das normas trabalhistas via acordo coletivo têm sido comprometidos por fatores que denotam a precarização das relações de trabalho, essencialmente no que se refere às garantias do trabalhador, amplamente assimilado na conjuntura econômica brasileira, como hipossuficiente.

Da mesma forma que a corrente doutrinária defende a flexibilização pelo fato de as relações de trabalho não serem estáticas, fazendo nascer a cada dia novos conflitos resultantes de acontecimentos sociais e econômicos, que implicam diretamente nestas relações e que necessitam ser regulamentadas e apreciadas pela sociedade e pelo Estado, a corrente contrária ao excesso do uso desta flexibilização, consideram que a abertura para flexibilizar indiscriminadamente é uma impropriedade a toda prova em um país como o Brasil, que é desigualmente desenvolvido, não possui sindicatos fortes para que o trabalhador não seja explorado tal como era na início do século XIX.

Apesar da concordância de que a legislação pátria poderia ter normas mais gerais do que atualmente, menos detalhista, menos intervencionista, não é admissível entre os doutrinadores admitir o prejuízo dos direitos historicamente conquistados sem que se observe o rebaixamento da dignidade do trabalhador como ser humano. Acredita-se indispensável proteger a integridade do trabalhador, cercando-o de garantias mínimas, cuja preservação é necessária para que o trabalhador possa crescer fisicamente, culturalmente e psicologicamente como pessoa digna. 
Os doutrinadores proclamam que a flexibilização das normas trabalhistas admitida pela Constituição Federal de 1988, não pode prejudicar a função protetora do Direito do Trabalho, uma vez que a proteção ao trabalhador está constitucionalmente garantida por valores que se sobrepõe ao plano contratual das relações do trabalho. A flexibilização, então significaria a mera adaptação através de leis mais elásticas, não podendo assemelhar-se à desregulamentação que é um processo de eliminação pura e simples desses direitos, oferecendo em troca a quimera da manutenção do subemprego.

Por isso tudo que o Projeto-lei n. 5.483/2001 é bastante polêmico, já que pretende serem as condições de trabalho ajustadas entre os trabalhadores e seus empregadores através de instrumentos coletivos (convenção ou acordo), prevalecendo sobre o disposto em lei. Por conta desse projeto haverá alteração legislativa proposta pela via ordinária que concederá às partes 0 imensurável poder de flexibilizar direitos trabalhistas encontrando o óbice intransponível da inconstitucionalidade, fazendo natimortas e de nenhum efeito, as cláusulas convencionais que possam resultar das respectivas negociações, que só encontrariam o necessário respaldo legal na própria constituição e desde que por ela autorizadas.

Entende-se que a evolução do Direito do Trabalho não dá margem para um desrespeito às garantias já conquistadas pelos trabalhadores, e a sua dignidade, pois estão de forma ampla e seguramente garantidas pela Constituição Federal de 1988.

Fica claro que o presente artigo não esgota o assunto que envolve a flexibilização das normas trabalhistas, mas procura colocar em evidência as causas do antagonismo que está sendo gerado a partir de um projeto de lei que sob a égide da flexibilização das normas trabalhistas esconde a tentativa de mitigar direitos há muito adquiridos pelos trabalhadores.

\section{Referências}

ANDRADE, E. G. L. de. Direito do trabalho e pos modernidade. São Paulo: LTr, 2005.

COSTA, M. S.Reestruturação produtiva, sindicatos e a flexibilização das relações de trabalho no Brasil. RAE-eletrônica, v. 2, n. 2, art. 10, p. 1-16, 2003. Disponível em; http://www.spell.org.br/documentos/ver/30245/reestruturacao-produtiva--sindicatos-e-aflexibilizacao-das-relacoes-de-trabalho-no-brasil/i/pt-br. Acesso em: 27 de outubro de 2020.

DIÁRIO DO SENADO FEDERAL. Intelligentia jurídica. Brasília, 12 dez. 2001. p. 30652. Disponível em: <www.intelligentiajuridica.com.br/v3/artigo_visualizar.php>. Acesso em: 5 mar. 2020.

FERREIRA, A. B. de H. Dicionário Aurélio Eletrônico, Versão 2.0, Nova Fronteira, 1996, CD ROM.

KREIN, J. D. O aprofundamento da flexibilização das relações de trabalho no Brasil nos anos 90. 2001. 230 f. Dissertação (Mestrado em Economia). Instituto de Economia. Universidade Estadual de Campinas. Instituto de Economia. Campinas.

MARTINS, S. P. Flexibilização das condições de trabalho. São Paulo: Atlas, 2005.

MORAES FILHO, E. Introdução ao direito do trabalho. 5. ed., São Paulo: LTr, 2000. 
MOTTA, J. C. L. da. Negociado ou legislado - uma análise crítica: o Projeto de Lei $n$ $5.483 / 2001$ e suas repercussões na ordem social vigente. Jus Navigandi, Teresina, v. 6 , n. 58, p 1-26. ago. 2002. Disponível em: <http://jus2.uol.com>. Acesso em: 10 mar. 2008

NASSAR, R. de N. S. Flexibilização do direito do trabalho. São Paulo: LTr. 1992.

ROBORTELLA, L C. A.. O moderno direito do trabalho. São Paulo, LTr, 2002.

ROMITA, A. S. Direitos fundamentais nas relações de trabalho. São Paulo: LTr. 2001.

RÜDIGER, Dorothée Susanne. Contrato coletivo e flexibilização do mercado de trabalho. Síntese Trabalhista. São Paulo, v.8, n. 110, p. 147-153, nov. 2001.

SOUZA, M. C. M. de. Flexibilização da jornada em turnos ininterruptos de revezamento mediante negociação coletiva. Revista Justiça do Trabalho. Brasília, v.18, n. 214, p. 221, out. 2001. 